\title{
Evaluation of Some Medicinal Herbs Cold Pressed Oils According Their Physicochemical Properties with Chemometry
}

\author{
Zeliha ÜSTÜN ARGON ${ }^{11}$, Ali GÖKYER², Zinar Pınar GÜMÜŞ³, \\ Mevlüt BÜYÜKHELVACIGILL ${ }^{2}$
}

${ }^{1}$ Biosystem Engineering, Necmettin Erbakan University, Konya, Turkey

${ }^{2}$ Zade\& Zade Vital Ibn-i Sina R\&D Center, Zade Vital Pharmaceuticals Inc., Konya, Turkey

${ }^{3}$ Institute on Drug Abuse, Toxicology and Pharmaceutical Sciences (BATI), Ege University, İzmir, Türkiye

Received: 05 May1s 2017 - Revised: 18 September 2017 - Accepted: 03 November 2017

\begin{abstract}
In this study, we investigated the effects of cold pressed oil on physicochemical properties of milk thistle (Silybum marianum), anise seed (Pimpinella anisum), fennel seed (Foeniculum vulgare), terebinth (Pistacia terebinthus), coriander (Coriandrum sativum) and nettle seed (Urtica dioica). Selected oils from Central Anatolia Regions, were investigated in terms of the fatty acid methyl esters (FAME) compositions, peroxide value (PV), free fatty acid (FFA), refraction index (RI) at $40^{\circ} \mathrm{C}$ and oilseed yields. The data obtained from the analyses were evaluated chemometrically. The diagrams obtained by basic component analysis (PCA) and hierarchical clustering analysis (HCA). According to PCA and HCA results, selected seed oils have different properties in terms of FAME, FFA, PV and RI. This suggests that each oil originates from the physicochemical properties of its unique pharmacological properties. As a result, in this study, data on the physicochemical properties of oils obtained from six medicinal plants was given. These results indicate that the seeds of the Central Anatolian region can be used as acceptable raw materials for herbal natural support products. These analyses can be used in order to assure the purity and quality parameters of seed oils. And FAME, PV, FFA and RI data can be good parameters to determine any adulteration to these oils by chemometric analysis.
\end{abstract}

Keywords: Cold-pressed oil, physicochemical properties, PCA, HCA

\section{INTRODUCTION}

There is growing interest in herbal preparations, such as oils from plant sources. Vegetable oils have been used since the beginning of history to fight diseases due to the positive effects on human health. Vegetable oils have significant antioxidant properties and unique phytochemicals. Since these oils have been used to treat certain health problems, there is a significant increase in the use of these oils not only in the food industry but also in medicine and cosmetics.

Traditional knowledge plays an important role in developing new medicines by obtaining ancient medical literature or folkloric medicine. Research on new drugs from herbal sources has led to the discovery of new clinically useful drugs. In particular, the developments experienced over the last two hundred years played a major role in the treatment of human diseases [1].

\footnotetext{
${ }^{1}$ Corresponding Author E-mail: aysegulmendi@gmail.com
} 
For treatment purposes plants, seeds and extracts from different parts of plants are used. The chosen plants for the study, milk thistle (Silybum marianum), anise seed (Pimpinella anisum), fennel seed (Foeniculum vulgare), terebinth (Pistacia terebinthus), coriander (Coriandrum sativum) and nettle seed (Urtica dioica), are used in traditional medicine for various purposes and scientific findings also revealed the wide pharmacological activities.

Among these oils, milk thistle is known mainly as hepatoprotective with antioxidant effects [2,3] Anise seed oil is showing gastrointestinal system, nervous system, endocrine system protective effects $[1,4,5]$. Fennel seed oil is found beneficial for menstrual pain [6], expectorant [7], antihelmintic [8] while terebinth is useful when it is applied externally for rheumatism [9], Herpes simplex [10], support for paralysis treatment [11]. Coriander oil is reported for the treatment of anxiety, and convulsion [12,13], Alzheimer's [14] and has hypoglycemic and hepatoprotective effects $[15,16]$. And nettle seed oil is reported by EMEA (2008) [17] as a herbal medicinal product used in seborrhoeic skin conditions and for the relief of minor articular pain. As a result of previous scientific studies of these medicinal plants, extensive collections of the pharmacology and chemistry of plants have emerged.

Cold press is a simple, ecological and energy-efficient method and for that reason, it is technically more economical and needs less work force than other extraction techniques. [18]. Furthermore, it is one of the best ways to produce high-quality oil. When compared with hot pressing and solvent extraction, the oil yield of the cold pressing method is lower [19]. In recent years, consumers are more interested in cold pressed oils owing to the fact that these have been safer, more nutritious and natural [20]. During the cold press process, neither heat treatment nor any organic solvent are used to obtain oil from the raw material and to protect physicochemical properties of the oil. Therefore, cold pressed seed oils have high dietary importance, its own sensory properties, and useful elements for health with significant chemical properties [21-23]. Thus, natural antioxidants and important phytochemicals such as tocopherols, fatty acids, sterols and antioxidant phenolic compounds are protected to a considerable extent in cold pressed oils [24-27].

\section{MATERIAL and METHODS}

\subsection{Seed oil samples}

Seed samples were provided from Central Anatolian suppliers and oil extracted from the seeds by using the cold pressed method at Zade Vital Pharmaceuticals Inc. The temperature was kept below 40 degrees Celsius and no chemical and heating process were used.

\subsection{Chemicals}

All the reagents were obtained from J.T. Baker, Riedel-de Haën and Sigma-Aldrich and they are either chromatographic or analytical grade. Millipore ultrapure water (Type I) was used for all analysis.

\subsection{Fatty acid methyl esters (FAME) analysis}

For fatty acid methyl esters (FAME) analysis a COI/T.20/Doc. No 33 for olive oils method was used. Retention time is used for fatty acid identification and the standard for determination of retention time was A 37 component mixture of FAME (Supelco). The quantitative analysis is done by determining the area ratio which is under the relevant peak to the sum of the areas under all the peaks for the fatty acids. An Agilent 6890 GC-FID system was used for FAME analysis. The column was chosen as a Supelco 2560 capillary column (100 $\mathrm{m} \times 0.25 \mathrm{~mm}$ ID $\times 0.2 \mu \mathrm{m}$ ) and split ratio was 1:100. Injection and detector temperatures were $250^{\circ} \mathrm{C}$ and $260^{\circ} \mathrm{C}$, respectively. The temperature program was as follows; the oven temperature is held at $140^{\circ} \mathrm{C}$ for $1 \mathrm{~min}$ and then, increased to $240^{\circ} \mathrm{C}$ at a rate of $4^{\circ} \mathrm{C} / \mathrm{min}$ and hold for $5 \mathrm{~min}$. 


\subsection{Free fatty acids (FFA), peroxide value (PV) and refractive index (RI)}

For free acid (FFA) content EP8 2.5.1 method, for peroxide value (PV) EP8 2.5.5 method is used. For refractive index EP8 2.2.6 method and Rudolph J57WR is used.

\subsection{Data analysis}

The multivariate data matrix includes results from the chosen samples represented by fatty acid methyl esters, free fatty acid, peroxide value and refractive index. Characterization and classification of seed oils were characterized and classified by chemometric methods, PCA (Ward's algorithmic method) and HCA (Euclidian distance). The multivariate analyses were done by using Minitab 15 Statistical Software. Prior to the chemometric analysis data and auto scaled variables were standardized. Results of PCA are visualized by scores and loading plots. The relevance between principal groupings and observations are showed clearly by using score plots. In other respects, loadings plot, indicate the significance of each variable for the results. The correlation between variables and cluster observations in the score plots are explained by plots also. In this study, the connection between seed oils and cluster observation groupings are shown in the dendrogram.

\section{RESULTS and DISCUSSIONS}

As pointed out above, 6 different seed oil samples were analyzed to reveal their fatty acids methyl esters content, free fatty acid, peroxide value and refractive index. It is difficult to interpret the complex data which also contain a large amount of information. Data of Fatty Acid Methyl Esters (FAME) Analysis, Free Fatty Acids (FFA), Peroxide value (PV) and Refractive Index (RI) were given in the SM 1. As shown in Figure 1, cold pressed seed oil separated into five different groups. Anise seed oil (ANS) and fennel oil (FNL) acted like one group because of their similar properties, as expected.

ANS and FNL are separated from other seeds distinctly and both of the seeds showed different clustering features within themselves. Milk thistle seed oil (MT), nettle seed oil (NTL), coriander oil (CRA) and terebinth oil (TB) not only separated from each other but also clustered. Evaluating the analysis results by score plot diagram it has been clearly seen that these oils show no similar properties and have their own special features. PC1 and PC2 have a positive effect on separating ANS and FNL from other oil. MT is separated with the positive effect of PC1, the impact of PC2 is also high. Separation of TB is affected by the negative effect of PC1 and PC2. For NTL and CRA, none of two basic elements have an effect but showed very similar results with each other. Splitting up NTL from CRA is with PC2 effect. 


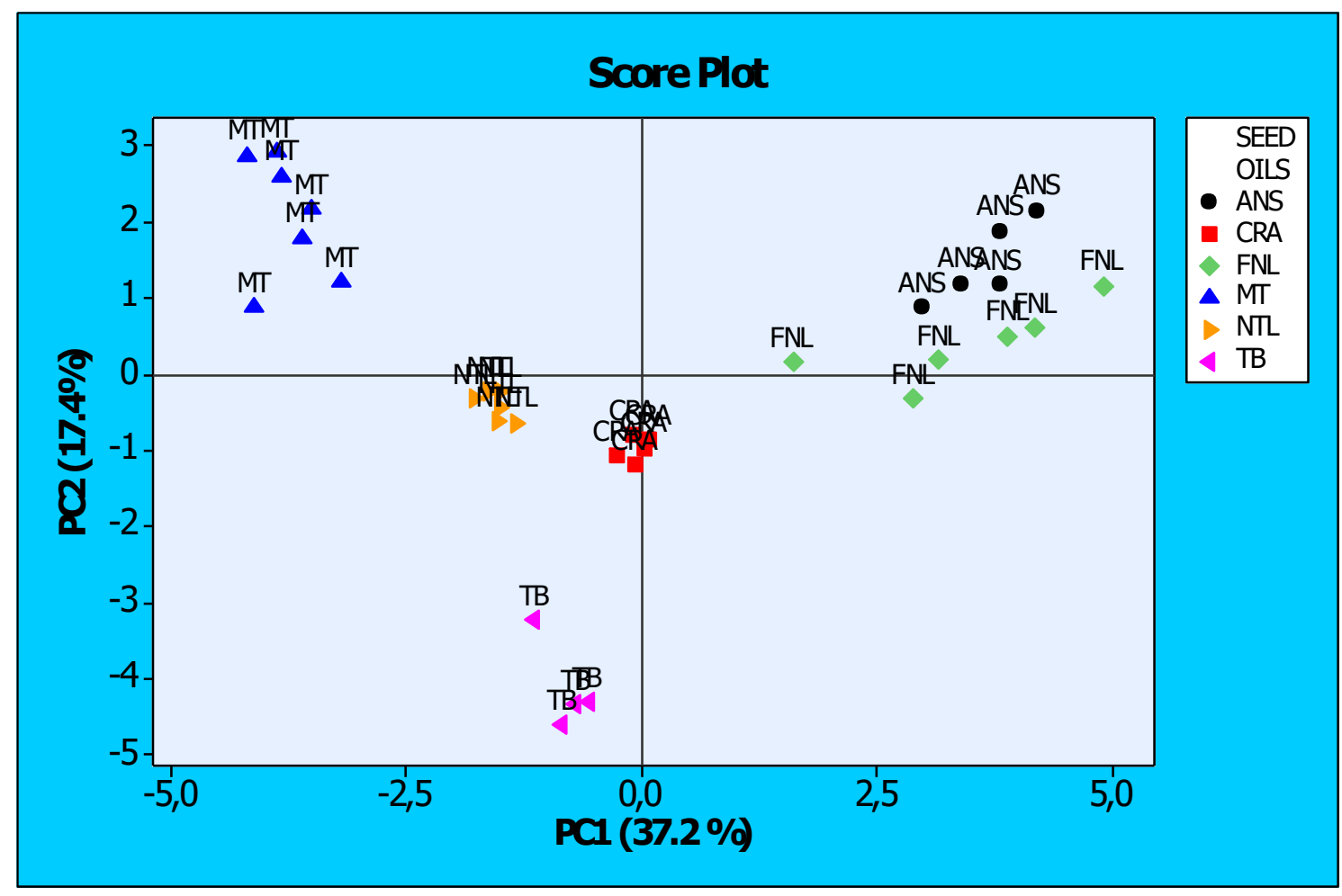

Figure 1. PCA score plot of fatty acid methyl esters for each seed oils.

The parameters which are affecting the seed oil differentiation can be seen with the score plot diagrams. RI is an effective physical parameter that can cause so the separation of ANS and FNL. FFA and PV are also effecting the separation. The alteration according to fatty acids is provided by short chain fatty acids and C18:1 and C18:3 fatty acids determined separation (Figure 2).

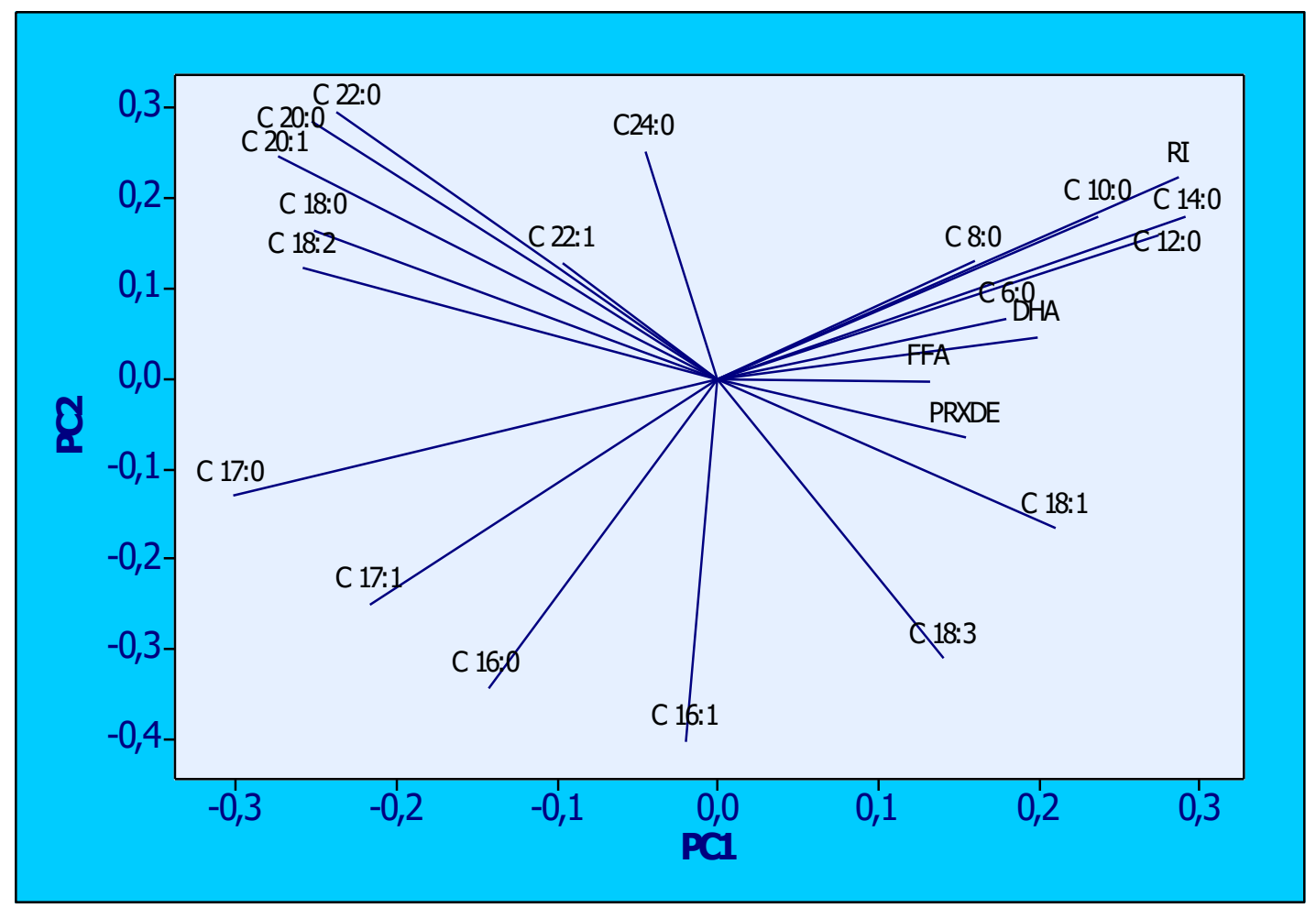

Figure 2. PCA loading plot of fatty acid methyl esters for each seed oils. 
Saturated fatty acids were found to be effective for MT. C18:2, C20:1 and C22:1 fatty acids provided separation of MT from other oils and its clustering. Separation of TB and CRA is found related with $\mathrm{C} 16: 0$ and $\mathrm{C} 16: 1$ fatty acid. C17:0 and C17:1 (odd carbon numbers) have effects on NTL.

At the last point, all data were evaluated by hierarchical cluster and analysis. The datasets were also auto-scaled using the Ward linkage method and the Euclidean distances. Sample inter-point distances and similarities are calculated by using normalized variables with the results in Figure 3. Referring to the dendogram it is seen clearly that the cold pressed oils with similar properties were clustered under the same group. The results were found to well correlated with the PCA outcomes.

Five different groups can be seen clearly by Hierarchical Cluster Analysis (HCA) dendrogram similar to PCA results. This results shows us according to the conducted analysis these oils can be separated from each other clearly.

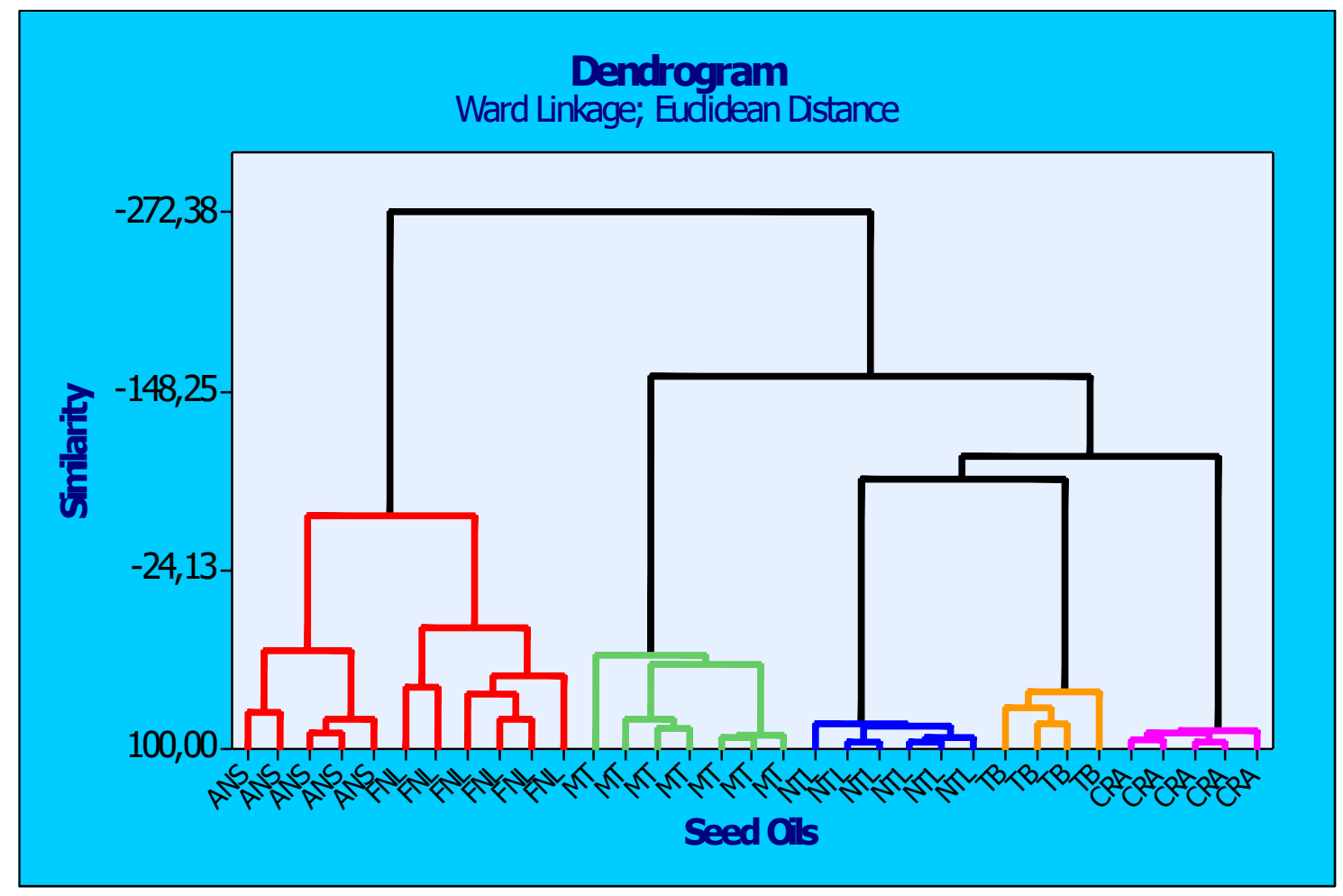

Figure 3. Cluster observations dendrogram of FAME, FFA, PV and RI according to the ward linkage, Euclidean distance with standardize variables for seed oils.

\section{CONCLUSION}

As result, it has been seen that the chosen seeds' cold pressed oils are differentiated from each other clearly according to FAME, FFA, PV and RI analyses. It can be said that an unknown seed oil sample can be recognized if it belongs one of the oils studied in the research by FAME, FFA, PV and RI analyses. So, if there is an adulteration with these oils, it can be recognized and the purity of seed oils can be assured. Beyond that FAME, FFA, PV, and RI properties are proved to be an effective tool to cluster the seed oils. In another point of view, these analyses can be used in quality control laboratories and production lines as they are intended to determine the purity and quality parameters of seed oils. It has been shown that the FAME, PV, FFA and $\mathrm{RI}$ analyses can be used to determine any adulteration to these oils by chemometric analysis. 
SM 1. Data of FAME, FFA, PV and RI values of seed oils.

\begin{tabular}{|c|c|c|c|c|c|c|c|c|c|c|c|c|c|c|c|c|c|c|c|c|c|c|}
\hline & C 6:0 & C 8:0 & C $10: 0$ & C 12:0 & C $14: 0$ & C $16: 0$ & $16: 1$ & C 17:0 & C $17: 1$ & 18:0 & C $18: 1$ & C $18: 2$ & C $18: 3$ & C 20:0 & C $20: 1$ & C 22:0 & C $22: 1$ & C24:0 & DHA & FFA & PRXDE & RI \\
\hline Anise 1 & 0,00 & 0,05 & 0,62 & 0,70 & 29,00 & 3,16 & 0,20 & 0,00 & 0,00 & 0,70 & 48,61 & 16,08 & 0,37 & 0,14 & 0,22 & 0,11 & 0,00 & 0,33 & 0,00 & 2,40 & 4,50 & 1,4878 \\
\hline Anise 2 & 0,00 & 0,03 & 0,71 & 0,42 & 22,98 & 3,46 & 0,27 & 0,00 & 0,00 & 0,89 & 52,09 & 17,69 & 0,52 & 0,10 & 0,10 & 0,07 & 0,00 & 0,28 & 0,00 & 2,45 & 5,40 & 1,4876 \\
\hline Anise 3 & 0,00 & 0,00 & 0,66 & 0,44 & 19,84 & 3,15 & 0,27 & 0,00 & 0,00 & 0,81 & 55,18 & 18,41 & 0,36 & 0,08 & 0,08 & 0,12 & 0,00 & 0,21 & 0,00 & 2,50 & 2,20 & 1,4841 \\
\hline Anise 4 & 0,00 & 0,00 & 0,99 & 0,68 & 30,22 & 2,86 & 0,24 & 0,00 & 0,00 & 0,70 & 46,36 & 16,29 & 0,40 & 0,07 & 0,07 & 0,05 & 0,00 & 0,57 & 0,00 & 1,90 & 1,80 & 1,4894 \\
\hline Anise 5 & 0,00 & 0,00 & 0,81 & 0,54 & 24,47 & 3,05 & 0,26 & 0,00 & 0,00 & 0,78 & 49,88 & 16,77 & 0,45 & 0,08 & 0,08 & 0,06 & 0,00 & 0,37 & 0,00 & 2,30 & 2,00 & 1,4862 \\
\hline Milk Thistle 1 & 0,00 & 0,00 & 0,00 & 0,00 & 0,09 & 7,88 & 0,13 & 0,08 & 0,12 & 0,08 & 0,12 & 55,01 & 0,13 & 3,50 & 0,80 & 2,20 & 0,03 & 0,05 & 0,00 & 0,07 & 0,08 & 1,4659 \\
\hline Milk Thistle 2 & 0,00 & 0,00 & 0,00 & 0,00 & 0,18 & 8,07 & 0,07 & 0,06 & 0,03 & 5,75 & 23,95 & 54,81 & 0,25 & 3,02 & 0,83 & 2,19 & 0,04 & 0,38 & 0,00 & 0,90 & 6,20 & 1,4658 \\
\hline Milk Thistle 3 & 0,00 & 0,00 & 0,00 & 0,00 & 0,14 & 8,79 & 0,05 & 0,07 & 0,03 & 6,01 & 25,38 & 52,23 & 0,10 & 3,37 & 0,75 & 1,87 & 0,03 & 0,03 & 0,00 & 1,90 & 4,80 & 1,4652 \\
\hline Milk Thistle 4 & 0,00 & 0,00 & 0,00 & 0,00 & 0,11 & 8,62 & 0,09 & 0,07 & 0,03 & 5,29 & 26,10 & 53,18 & 0,32 & 2,66 & 0,78 & 1,77 & 0,03 & 0,05 & 0,00 & 2,00 & 4,00 & 1,4658 \\
\hline Milk Thistle 5 & 0,00 & 0,00 & 0,00 & 0,00 & 0,08 & 7,74 & 0,07 & 0,08 & 0,04 & 5,05 & 29,20 & 49,08 & 0,13 & 3,35 & 0,99 & 2,59 & 0,03 & 0,74 & 0,00 & 3,73 & 1,50 & 1,4681 \\
\hline Milk Thistle 6 & 0,00 & 0,00 & 0,00 & 0,00 & 0,09 & 7,84 & 0,08 & 0,08 & 0,04 & 5,54 & 24,84 & 52,10 & 0,19 & 3,70 & 0,98 & 2,64 & 0,03 & 0,71 & 0,00 & 2,76 & 0,60 & 1,4654 \\
\hline Milk Thistle 7 & 0,00 & 0,00 & 0,00 & 0,00 & 0,08 & 7,77 & 0,07 & 0,07 & 0,03 & 5,08 & 24,26 & 54,68 & 0,15 & 3,26 & 0,89 & 2,32 & 0,03 & 0,60 & 0,00 & 2,87 & 1,00 & 1,4656 \\
\hline Fennel 1 & 0,00 & 0,00 & 0,00 & 0,00 & 20,66 & 3,67 & 0,16 & 0,03 & 0,00 & 1,33 & 62,98 & 9,38 & 0,55 & 0,16 & 0,26 & 0,09 & 0,01 & 0,07 & 1,82 & 3,03 & 25,00 & 1,4828 \\
\hline Fennel 2 & 0,00 & 0,00 & 0,00 & 0,00 & 0,11 & 4,82 & 0,14 & 0,02 & 0,00 & 1,75 & 75,37 & 12,36 & 0,51 & 0,29 & 0,53 & 0,17 & 0,09 & 0,17 & 1,72 & 1,10 & 30,00 & 1,4822 \\
\hline Fennel 3 & 1,81 & 0,01 & 0,33 & 1,46 & 16,07 & 3,73 & 0,05 & 0,02 & 0,00 & 1,16 & 60,76 & 9,51 & 0,46 & 0,16 & 0,30 & 0,09 & 0,01 & 0,07 & 1,54 & 5,30 & 18,30 & 1,4809 \\
\hline Fennel 4 & 1,34 & 0,00 & 0,21 & 0,79 & 21,29 & 3,74 & 0,05 & 0,03 & 0,00 & 1,16 & 57,65 & 11,31 & 0,47 & 0,14 & 0,07 & 0,06 & 0,01 & 0,05 & 1,50 & 2,20 & 12,50 & 1,4804 \\
\hline Fennel 5 & 0,68 & 0,00 & 0,13 & 0,58 & 11,83 & 4,02 & 0,06 & 0,02 & 0,00 & 1,25 & 68,01 & 10,75 & 0,41 & 0,16 & 0,10 & 0,09 & 0,01 & 0,08 & 1,65 & 3,10 & 10,60 & 1,4775 \\
\hline Fennel 6 & 0,78 & 0,01 & 0,15 & 0,74 & 15,57 & 4,04 & 0,06 & 0,03 & 0,00 & 1,38 & 63,21 & 11,12 & 0,42 & 0,19 & 0,09 & 0,11 & 0,02 & 0,09 & 1,80 & 11,20 & 11,40 & 1,4862 \\
\hline Nettle 1 & 0,00 & 0,00 & 0,00 & 0,00 & 0,06 & 7,06 & 0,06 & 0,06 & 0,03 & 3,89 & 20,22 & 66,99 & 0,48 & 0,39 & 0,33 & 0,08 & 0,00 & 0,02 & 0,00 & 1,11 & 10,80 & 1,4678 \\
\hline Nettle 2 & 0,00 & 0,00 & 0,00 & 0,00 & 0,06 & 7,20 & 0,05 & 0,06 & 0,03 & 3,88 & 20,76 & 66,62 & 0,31 & 0,55 & 0,32 & 0,07 & 0,00 & 0,02 & 0,00 & 1,60 & 1,80 & 1,4677 \\
\hline Nettle 3 & 0,00 & 0,00 & 0,00 & 0,00 & 0,05 & 7,13 & 0,05 & 0,06 & 0,03 & 3,47 & 18,44 & 69,54 & 0,31 & 0,50 & 0,29 & 0,05 & 0,00 & 0,02 & 0,00 & 0,90 & 3,40 & 1,4679 \\
\hline Nettle 4 & 0,00 & 0,00 & 0,00 & 0,00 & 0,06 & 7,13 & 0,06 & 0,07 & 0,03 & 3,79 & 20,56 & 66,76 & 0,51 & 0,37 & 0,33 & 0,09 & 0,00 & 0,02 & 0,00 & 1,35 & 1,20 & 1,4677 \\
\hline Nettle 5 & 0,00 & 0,00 & 0,00 & 0,00 & 0,05 & 6,64 & 0,05 & 0,07 & 0,03 & 3,80 & 20,07 & 67,72 & 0,45 & 0,36 & 0,50 & 0,08 & 0,00 & 0,02 & 0,00 & 0,97 & 1,10 & 1,4677 \\
\hline Nettle 6 & 0,00 & 0,00 & 0,00 & 0,00 & 0,06 & 6,89 & 0,05 & 0,06 & 0,03 & 3,88 & 19,62 & 68,21 & 0,44 & 0,34 & 0,33 & 0,08 & 0,00 & 0,02 & 0,00 & 1,50 & 2,80 & 1,4678 \\
\hline Terebinth 1 & 0,00 & 0,00 & 0,00 & 0,00 & 0,09 & 22,57 & 3,10 & 0,06 & 0,03 & 2,19 & 49,87 & 20,70 & 0,80 & 0,17 & 0,21 & 0,05 & 0,00 & 0,06 & 0,00 & 2,60 & 3,50 & 1,4621 \\
\hline Terebinth 2 & 0,00 & 0,00 & 0,00 & 0,00 & 0,05 & 21,18 & 3,55 & 0,06 & 0,09 & 1,84 & 52,32 & 19,91 & 0,56 & 0,15 & 0,19 & 0,05 & 0,00 & 0,05 & 0,00 & 3,03 & 10,80 & 1,4627 \\
\hline Terebinth 3 & 0,00 & 0,00 & 0,00 & 0,00 & 0,06 & 19,70 & 2,75 & 0,09 & 0,08 & 1,74 & 56,81 & 17,71 & 0,61 & 0,11 & 0,18 & 0,07 & 0,00 & 0,07 & 0,00 & 5,55 & 10,40 & 1,4630 \\
\hline
\end{tabular}


International Journal of Secondary Metabolite, Vol. $4: 3$ (2017) pp. 473-481

\begin{tabular}{|c|c|c|c|c|c|c|c|c|c|c|c|c|c|c|c|c|c|c|c|c|c|c|}
\hline Terebinth 4 & 0,00 & 0,00 & 0,00 & 0,00 & 0,05 & 18,92 & 1,40 & 0,08 & 0,09 & 1,81 & 54,55 & 20,44 & 0,75 & 0,13 & 0,29 & 0,04 & 0,00 & 0,55 & 0,00 & 2,00 & 4,00 & 1,4630 \\
\hline Coriander 1 & 0,00 & 0,00 & 0,00 & 0,00 & 0,04 & 3,26 & 0,21 & 0,05 & 0,06 & 0,69 & 81,66 & 13,22 & 0,20 & 0,05 & 0,25 & 0,04 & 0,04 & 0,04 & 0,00 & 1,30 & 2,80 & 1,4632 \\
\hline Coriander 2 & 0,00 & 0,00 & 0,00 & 0,00 & 0,03 & 3,55 & 0,25 & 0,04 & 0,06 & 0,84 & 80,60 & 13,95 & 0,26 & 0,09 & 0,15 & 0,04 & 0,04 & 0,05 & 0,00 & 0,73 & 2,10 & 1,4634 \\
\hline Coriander 3 & 0,00 & 0,00 & 0,00 & 0,00 & 0,03 & 3,35 & 0,23 & 0,03 & 0,05 & 0,75 & 80,51 & 14,17 & 0,20 & 0,09 & 0,32 & 0,04 & 0,04 & 0,04 & 0,00 & 1,60 & 1,20 & 1,4633 \\
\hline Coriander 4 & 0,00 & 0,00 & 0,00 & 0,00 & 0,03 & 3,33 & 0,17 & 0,03 & 0,05 & 0,89 & 81,18 & 13,95 & 0,13 & 0,10 & 0,15 & 0,04 & 0,04 & 0,04 & 0,00 & 0,98 & 7,50 & 1,4631 \\
\hline Coriander 5 & 0,00 & 0,00 & 0,00 & 0,00 & 0,06 & 3,68 & 0,25 & 0,03 & 0,05 & 0,80 & 78,11 & 14,10 & 0,26 & 0,10 & 0,27 & 0,05 & 0,04 & 0,04 & 0,00 & 1,80 & 2,50 & 1,4634 \\
\hline
\end{tabular}




\section{Acknowledgement}

This study is supported by Zade \& Zade Vital İbn-i Sina R\&D Center and Zade Vital Pharmaceuticals Inc.

\section{Conflict of Interests}

Authors declare that there is no conflict of interests.

\section{REFERENCES}

[1]. Karimzadeh, F., Hosseini, M., Mangeng, D., Alavi, H., Hassanzadeh, G. R., Bayat, M. \& Gorji, A. (2012). Anticonvulsant and neuroprotective effects of Pimpinella anisum in rat brain. BMC complementary and alternative medicine, 12(1), 76.

[2]. Hermenean, A., Stan, M., Ardelean, A., Pilat, L., Mihali, C. V., Popescu, C. \& Bácskay, I. (2015). Antioxidant and hepatoprotective activity of milk thistle (Silybum marianum L. Gaertn.) seed oil. Open Life Sciences, 10(1).

[3]. Kaur, A. K., Wahi, A. K., Brijesh, K., Bhandari, A., \& Prasad, N. (2011). Milk thistle (Silybum marianum): A review. IJPRD, 3, 1-10.

[4]. Shojaii, A., \& Abdollahi Fard, M. (2012). Review of pharmacological properties and chemical constituents of Pimpinella anisum. ISRN pharmaceutics, 2012.

[5]. EMEA Committee on Herbal Medicinal Products (HMPC) (2012) Assessment report on Pimpinella anisum L., fructus and Pimpinella anisum L., aetheroleum, EMEA/HMPC/321181/2012.

[6]. EMEA Committee on Herbal Medicinal Products (HMPC) (2008) Assessment Report on Foeniculum Vulgare Miller, EMEA/HMPC/137426/2006.

[7]. Blumethal, M., Busse, W. R., \& Goldberg, A. (1998). The complete German Commission $\mathrm{E}$ monographs. American Botanical Council, Austin and Integrative Medicine Communications, Boston.

[8]. Wakabayashi, K. A., de Melo, N. I., Aguiar, D. P., de Oliveira, P. F., Groppo, M., da Silva Filho, A. A., ... \& Crotti, A. E. (2015). Anthelmintic effects of the essential oil of fennel (Foeniculum vulgare Mill., Apiaceae) against Schistosoma mansoni. Chemistry \& biodiversity, 12(7), 1105-1114.

[9]. Bozorgi, M., Memariani, Z., Mobli, M., Salehi Surmaghi, M. H., Shams-Ardekani, M. R., \& Rahimi, R. (2013). Five Pistacia species (P. vera, P. atlantica, P. terebinthus, P. khinjuk, and P. lentiscus): a review of their traditional uses, phytochemistry, and pharmacology. The Scientific World Journal, 2013.

[10]._Pieroni, A., Muenz, H., Akbulut, M., Başer, K. H. C., \& Durmuşkahya, C. (2005). Traditional phytotherapy and trans-cultural pharmacy among Turkish migrants living in Cologne, Germany. Journal of ethnopharmacology, 102(1), 69-88.

[11]. Ntalli, N. G., Ferrari, F., Giannakou, I., \& Menkissoglu-Spiroudi, U. (2011). Synergistic and antagonistic interactions of terpenes against Meloidogyne incognita and the nematicidal activity of essential oils from seven plants indigenous to Greece. Pest management science, 67(3), 341-351.

[12]. Sahib, N. G., Anwar, F., Gilani, A. H., Hamid, A. A., Saari, N., \& Alkharfy, K. M. (2013). Coriander (Coriandrum sativum L.): A Potential Source of High-Value Components for Functional Foods and Nutraceuticals-A Review. Phytotherapy Research, 27(10), 14391456. 
[13]. Emamghoreishi, M., \& Heidari-Hamedani, G. (2015). Sedative-hypnotic activity of extracts and essential oil of coriander seeds. Iranian Journal of Medical Sciences, 31(1), 22-27.

[14]. Cioanca, O., Hritcu, L., Mihasan, M., \& Hancianu, M. (2013). Cognitive-enhancing and antioxidant activities of inhaled coriander volatile oil in amyloid $\beta$ (1-42) rat model of Alzheimer's disease. Physiology \& behavior, 120, 193-202.

[15]. Samojlik, I., Lakić, N., Mimica-Dukić, N., Đaković-Švajcer, K., \& Božin, B. (2010). Antioxidant and hepatoprotective potential of essential oils of coriander (Coriandrum sativum L.) and caraway (Carum carvi L.) (Apiaceae). Journal of Agricultural and Food Chemistry, 58(15), 8848-8853.

[16]. Burdock, G. A., \& Carabin, I. G. (2009). Safety assessment of coriander (Coriandrum sativum L.) essential oil as a food ingredient. Food and Chemical Toxicology, 47(1), 2234.

[17]. EMEA Committee on Herbal Medicinal Products (HMPC). (2008) Assessment Report on Foeniculum Vulgare Miller, Committee on Herbal Medicinal Products, EMEA/HMPC/137426/2006.

[18]. Nam U.G., \& Nam D. (2016) Some physicochemical properties, fatty acid composition and antimicrobial characteristics of different cold-pressed oils, La rivista italiana delle sostanze grasse, XCII, 187-200.

[19]. Yilmaz, E., Aydeniz, B., Güneşer, O., \& Arsunar, E. S. (2015). Sensory and PhysicoChemical Properties of Cold Press-Produced Tomato (Lycopersicon esculentum L.) Seed Oils. Journal of the American Oil Chemists' Society, 92(6), 833-842.

[20]. Thanonkaew, A., Wongyai, S., McClements, D. J., \& Decker, E. A. (2012). Effect of stabilization of rice bran by domestic heating on mechanical extraction yield, quality, and antioxidant properties of cold-pressed rice bran oil (Oryza saltiva L.). LWT-Food science and technology, 48(2), 231-236.

[21]. Argon Z., \& Gokyer A. (2016) Determination of Physicochemical Properties of Nigella sativa Seed Oil from Balıkesir Region, Turkey, Chemical and Process Engineering Research, 41, 43-46.

[22]. Topkafa, M. (2016). Evaluation of chemical properties of cold pressed onion, okra, rosehip, safflower and carrot seed oils: triglyceride, fatty acid and tocol compositions. Analytical Methods, 8(21), 4220-4225.

[23]. Gharibzahedi, S. M. T., Mousavi, S. M., Hamedi, M., Rezaei, K., \& Khodaiyan, F. (2013). Evaluation of physicochemical properties and antioxidant activities of Persian walnut oil obtained by several extraction methods. Industrial crops and products, 45, 133-140.

[24]. Lutterodt, H., Slavin, M., Whent, M., Turner, E., \& Yu, L. L. (2011). Fatty acid composition, oxidative stability, antioxidant and antiproliferative properties of selected cold-pressed grape seed oils and flours. Food Chemistry, 128(2), 391-399.

[25]. Bozan, B., \& Temelli, F. (2008). Chemical composition and oxidative stability of flax, safflower and poppy seed and seed oils. Bioresource Technology, 99(14), 6354-6359.

[26]. Kozłowska, M., Gruczyńska, E., Ścibisz, I., \& Rudzińska, M. (2016). Fatty acids and sterols composition, and antioxidant activity of oils extracted from plant seeds. Food chemistry, 213, 450-456.

[27]. Gumus, Z. P., Guler, E., Demir, B., Barlas, F. B., Yavuz, M., Colpankan, D., \& Timur, S. (2015). Herbal infusions of black seed and wheat germ oil: Their chemical profiles, in vitro bio-investigations and effective formulations as phyto-nanoemulsions. Colloids and Surfaces B: Biointerfaces, 133, 73-80. 